SHORT COMMUNICATION

\title{
STUDY ON THE LEAD POLLUTION CAUSED BY AUTOMOBILE EXHAUST IN SYLHET CITY
}

SHAMSHAD B. QURAISHI*

Chemistry Division, Atomic Energy Centre, P.O. 164. Ramna, Dhaka-1000

SHAHIDUL ISLAM AND MUHAMMAD YOUNUS

Department of Chemistry, Shahjalal University of Science and Technology, Sylhet

Environmental pollution is a major concern nowadays in all over the world. As Bangladesh is a densely populated country, environmental pollution phenomena have a great impact here. The main sources of air pollution in Bangladesh are automobiles engines including two-stock and four-stock engines (i.e. bus, truck, tempo, autorickshawas, motor cycles etc.), uncontrolled industrialization, fertilizer industry, chemical plants, garments, brick-fields and other industries ${ }^{(1,2)}$. It is notable that the concentration of $\mathrm{Pb}$ in the ambient air of Dhaka city has decreased by two-three times as a result of the introduction of unleaded gasoline by the Energy Ministry from July 1, 1999. ${ }^{(2)}$ However, $\mathrm{Pb}$ is still being used in an uncontrolled manner in different industries.

Sylhet city is an old and congested city and roads in the town are very narrow and highly traffic dense. Unfortunately, no study has been carried out yet on atmospheric pollution of Sylhet city. In the present study the Pb levels in the leaf and soil samples collected from six heavy traffic dense areas of Sylhet city are reported to get an overview of lead pollution phenomena and its relation to environment.

\section{EXPERIMENTAL}

Leaf and soil samples were collected from different locations of the Sylhet city where traffic density is generally very high due to Tempo, Bus and Truck stands. The samples were collected from 1) West Kadamtoli Bus stand, 2) East Kadamtoli Bus stand, 3) Lauai Bus stand, 4) Bandarbazar Point Tempo stand, 5) East Bandarbazar Point Tempo stand, 6) Supanighat Truck stand, and 7) Ambarkhana point area of the Sylhet city in January. The sampling locations are shown in Figure 1. One soil and one leaf sample were also collected from the Borgul Village. Akhalia of the Sylhet city that was used to compare the pollution status.

Collection and Preservation of Leaf sample : Vegetation and soils are important sinks for atmospheric pollutants. Indeed, the vegetative components are useful bio-monitor of atmospheric pollutant deposition. Therefore, leaves from different Tempo and Bus Stands

* Corresponding Author. E-mail:mumu3222@yahoo.com 


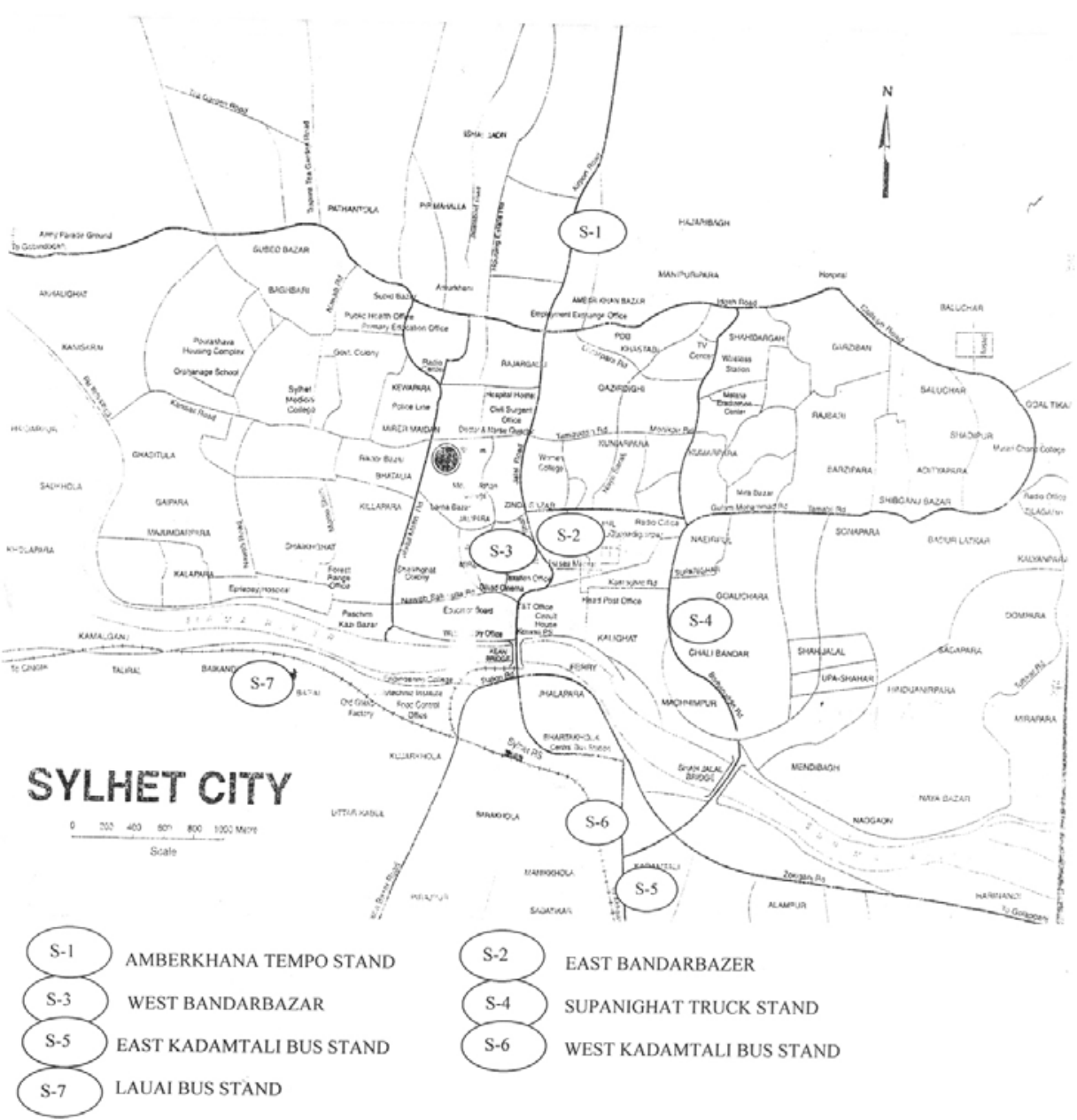

Fig. 1. Map of Sylhet city and collection points

trees were collected from the tree and cut into small pieces according to published procedure ${ }^{(3.4)}$ and mixed up very well and a portion of them was selected as sample. For each location only one kind of tree was selected. The selected trees were Jackfruit, Rain tree, Teak, Mango, and Banyan tree. Samples’ details are given in Table 1.

The leaf samples were dried in oven at $105^{\circ} \mathrm{C}$ and then ground to powder with aluminum carbide mortar and were preserved in previously cleaned polythene bags.

Soil sample: The collected soil samples were oven dried at $105^{\circ} \mathrm{C}$ until constant weight was obtained. The soil samples were homogenized using an agate mortar and passed through $1 \mathrm{~mm}$ sieves. The dried samples were preserved in previously cleaned polythene bags.

\section{Acid Digestion}


Leaf sample digestion process : The leaf sample (1g) was ashed by heating in a muffle furnace at $450^{\circ} \mathrm{C}$ for 6 hours in a $25 \mathrm{ml}$ pyrex beaker. To the ash $4 \mathrm{ml}$ of analytical grade nitric acid was added (one $\mathrm{ml}$ at a time) and digested to nearly dryness for at least 5 hours on water bath. Further one $\mathrm{ml}$ of aqua regia ( $3: 1$ of $\mathrm{HCI}$ and $\mathrm{HNO}_{3}$ ) was added and continued digestion and evaporated to dryness ${ }^{5}$. Finally, 2-3 drops of concentrated nitric acid was added and then warmed with $5 \mathrm{ml}$ of de-ionized water. The solution was filtered with Whatman-41 filter paper, diluted to $10 \mathrm{ml}$ in $10 \mathrm{ml}$ volumetric flask using de-ionized water.

Soil sample digestion process: To $0.5 \mathrm{~g}$ of finely ground soil sample $3 \mathrm{ml}$ of aqua regia was added and the sample was kept overnight. The mixture was digested on a water bath and $7 \mathrm{ml}$ of aqua regia was gradually added (one $\mathrm{ml}$ at time) and the sample was digested for 7 hours at $90^{\circ} \mathrm{C}$ and the solution was evaporated nearly to dryness. Ten ml of $0.1 \mathrm{M}$ Na-EDTA solution was added and adjusted the $\mathrm{pH}$ at 5 to 6 by using hydrochloric acid or sodium hydroxide solution. The solution was allowed to stand for two hours and then filtered through Whatman-41 filter paper. The filtrate was evaporated to some extent so as to make a $10 \mathrm{ml}$ solution with distilled deionised water. Samples ware then analyzed for metals by FAAS. In every case a duplicate and a parallel blank experiment were carried out for the accurate determination of lead. The quantitation limit for the $\mathrm{Pb}$ was calculated as $2.1 \mathrm{ppm}$ in leaf and $4.0 \mathrm{ppm}$ in soil, respectively.

\section{RESULTS AND DISCUSSION}

The concentrations of lead in leaves in the different locations of Shlhet city are given in Table 1. The content of lead in leaves was found in the range 5.72-121 ppm. The lowest lead content in leaves was found in central Bandarbazar tempo stand (5.7 ppm) and the highest $\mathrm{Pb} 121 \mathrm{ppm}$ at Amberkhana tempo stand. This may be due to the difference in traffic density. The average traffic load at Ambarkhana Tempo Stand, East Kadamtoli Bus stand, Lauai Bus stand, West Kadamtili Bus stand, East Bandarbazar Tempo stand, Supanighat Truck stand and Bandarbazar Tempo stand were 27, 11, 7, 4, 3, 3 , and 3 vehicles/min, respectively whereas the lead content in reference leaf sample, which was collected from the remote area in the city, was below experimental detection limit ( $<2.1 \mathrm{ppm})$ indicating these leaves are not exposed to lead.

The lead content in soils varied from 9.93-176.47 ppm (Table 1). The lowest lead content was found in Supanighat Truck stand (9.93ppm)and the highest in Ambarkhana tempo stand (176.47 ppm), although detected level was found to be $8.09 \mathrm{ppm}$ from the country side.

Table 1

Lead content in leaf and soil in sylhet city

Sample Sampling locations $\quad$ Leaf type $\quad$ Lead content in $\quad$ Lead content in




\begin{tabular}{lllll}
\hline Code & & & $\begin{array}{c}\text { leaves (ppm) } \\
\text { SD* }\end{array}$ & soil (ppm) \pm SD* $^{*}$ \\
\hline S-1 & Amberkhana Tempo stand & Jackfruit tree & $121 \pm 1.2$ & $176 \pm 2.05$ \\
S-2 & $\begin{array}{l}\text { Bandarbazar Tempo stand } \\
\text { (East) }\end{array}$ & Teak tree & $12.65 \pm 0.67$ & $35.29 \pm 0.87$ \\
& Bandarbazar Tempo stand & Rain tree & $5.72 \pm 0.52$ & $79.37 \pm 1.21$ \\
S-3 & (West) & Mango tree & $10.95 \pm 0.5$ & $9.93 \pm 0.61$ \\
& Supanighat Truck stand & $55.56 \pm 0.42$ & $88.24 \pm 1.3$ \\
S-4 & Kadamtoli Bus stand (East) & Rain tree & $111 \pm 2.1$ \\
S-5 & Kadamtoli Bus stand & Rain tree & $19.97 \pm 0.51$ & $111 \pm 1.54$ \\
S-6 & (West) & Banyan tree & $25.04 \pm 0.98$ & $8.09 \pm 0.34$ \\
S-7 & Lauai Bus stand & Jackfruit tree & $<2.1$ & \\
S-8 & Reference Sample (Borgul & & & \\
& Village, Akhalia) & & & \\
\hline
\end{tabular}

* Standard deviations (SD) have been calculated from triplicate measurements

The lead levels obtained from the study (5.72-121ppm) were considerably lower compared to reported lead concentrations in Dhaka ${ }^{(7)}$ (leaves $8.432 \mathrm{ppm}$ ), Benin ${ }^{3}$ (vegetable 243 ppm) and Bagdad $^{(8)}$ (palm leaves 28-1000 ppm).

It can be said that the air of the Sylhet city is not much lead polluted and not an immediate threat to environment but getting polluted in some areas of the city.

\section{REFERENCES}

1. M. Khaliquzzaman, S. K Biswas, S. A. Tarafder, A. Islam, and A. H. Khan, AECD/AFD-CH/3-44, Technical Report, Bangladesh Atomic Energy Commission, Bangladesh, 1995.

2. M. Khaliquzzaman, S. K Biswas, S. A. Tarafder, and A. Islam, AECD/AFD-CH/9-50, Technical Report, Bangladesh Atomic Energy Commission, Bangladesh, 1999.

3. C. L. NDIOKWERE, Environ. Pollut., 7, 35-42, 1984.

4. R. HibBen, S. H. Silan, Environ. Pollut., 7, 71-80, 1984.

5. D. A. Hadi, S. A Tarafdar, S. AKhter And Y. Mia, Bang. J. Sci. Res., 13, 221-223, 1995.

6. S. B. QURAISHI, AND S. AKHTER, J. Bang. Acad. of Sci., 29, 163-171, 2005.

7. A. I. Mustafa, M. A. Hossain, M. M. Rahman, and M. Alam, Dhaka Univ.Stu. 41, 133138, 1993.

8. A. A. K. HanA, Water, Air and Soil Pollut., 19, 3-14, 1983.

Journal of Bangladesh Academy of Sciences, Vol. 32, No. 2, 117-120, 2008 